\title{
Strategies to facilitate exposure to internet-delivered health behavior change interventions aimed at adolescents or young adults: a systematic review.
}

Citation for published version (APA):

Crutzen, R., de Nooijer, J. M., Brouwer, W., Oenema, A., Brug, J., \& de Vries, N. K. (2011). Strategies to facilitate exposure to internet-delivered health behavior change interventions aimed at adolescents or young adults: a systematic review. Health Education \& Behavior, 38(1), 49-62. https://doi.org/10.1177/1090198110372878

Document status and date:

Published: 01/01/2011

DOI:

10.1177/1090198110372878

Document Version:

Publisher's PDF, also known as Version of record

Please check the document version of this publication:

- A submitted manuscript is the version of the article upon submission and before peer-review. There can be important differences between the submitted version and the official published version of record.

People interested in the research are advised to contact the author for the final version of the publication, or visit the DOI to the publisher's website.

- The final author version and the galley proof are versions of the publication after peer review.

- The final published version features the final layout of the paper including the volume, issue and page numbers.

Link to publication

\footnotetext{
General rights rights.

- You may freely distribute the URL identifying the publication in the public portal. please follow below link for the End User Agreement:

www.umlib.nl/taverne-license

Take down policy

If you believe that this document breaches copyright please contact us at:

repository@maastrichtuniversity.nl

providing details and we will investigate your claim.
}

Copyright and moral rights for the publications made accessible in the public portal are retained by the authors and/or other copyright owners and it is a condition of accessing publications that users recognise and abide by the legal requirements associated with these

- Users may download and print one copy of any publication from the public portal for the purpose of private study or research.

- You may not further distribute the material or use it for any profit-making activity or commercial gain

If the publication is distributed under the terms of Article $25 \mathrm{fa}$ of the Dutch Copyright Act, indicated by the "Taverne" license above, 


\section{Health Education \& Behavior \\ http://heb.sagepub.com/}

\section{Strategies to Facilitate Exposure to Internet-Delivered Health Behavior Change Interventions Aimed at Adolescents or Young Adults: A Systematic Review}

Rik Crutzen, Jascha de Nooijer, Wendy Brouwer, Anke Oenema, Johannes Brug and Nanne K. de Vries Health Educ Behav 2011 38: 49 originally published online 28 December 2010

DOI: $10.1177 / 1090198110372878$

The online version of this article can be found at:

http://heb.sagepub.com/content/38/1/49

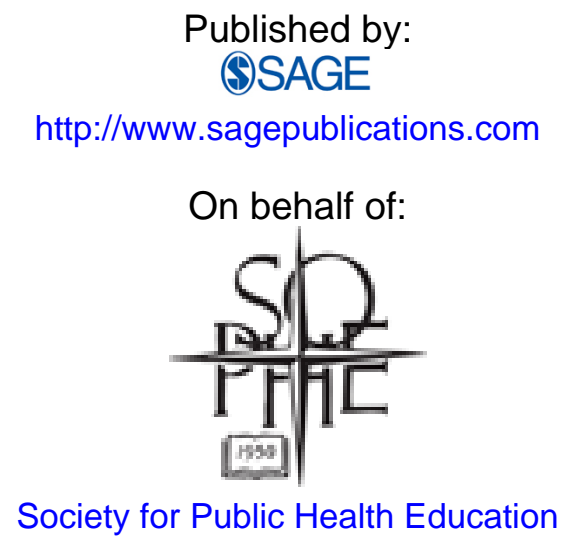

Additional services and information for Health Education \& Behavior can be found at:

Email Alerts: http://heb.sagepub.com/cgi/alerts

Subscriptions: http://heb.sagepub.com/subscriptions

Reprints: http://www.sagepub.com/journalsReprints.nav

Permissions: http://www.sagepub.com/journalsPermissions.nav

Citations: http://heb.sagepub.com/content/38/1/49.refs.html 


\title{
Strategies to Facilitate Exposure to Internet-Delivered Health Behavior Change Interventions Aimed at Adolescents or Young Adults: A Systematic Review
}

Health Education \& Behavior

38(I) 49-62

(c) 2011 by SOPHE

Reprints and permission: sagepub.com/journalsPermissions.nav DOI: $10.1177 / 1090198110372878$

http://heb.sagepub.com

@SAGE

\author{
Rik Crutzen', Jascha de Nooijer', Wendy Brouwer², Anke Oenema², \\ Johannes Brug ${ }^{3}$, and Nanne K. de Vries'
}

\begin{abstract}
The Internet is considered to be a promising delivery channel of interventions aimed at promoting healthful behaviors, especially for adolescents and young adults. Exposure to these interventions, however, is generally low. A more extensive exploration of methods, strategies, and their effectiveness with regard to facilitating exposure is therefore timely, because this knowledge is crucial to improve the use of such interventions and, subsequently, to increase behavioral change. Therefore, a systematic review of the literature was conducted, resulting in 838 studies based on title selection, of which 26 studies met the eligibility criteria. The systematic review resulted in an overview of methods and strategies that have been used to facilitate exposure. Patterns of effective strategies could be observed, such as the combination of tailored communication and the use of reminders and incentives. Nevertheless, exposure-specific theories need to be developed and objective exposure measures should be tracked and reported in future studies.
\end{abstract}

\section{Keywords}

Internet-delivered interventions, exposure, adolescents, young adults

\section{Introduction}

The Internet holds the promise of reaching large numbers of people and is very suitable to deliver interventions aimed at primary prevention of physical chronic diseases through health behavior change (Bernhardt \& Hubley, 2001). Internet-delivered interventions may be particularly suitable to reach the current generation of adolescents and young adults, because this generation grew up with the Internet (Roberts \& Foehr, 2008) and are probably more open toward new possibilities offered by this medium than today's adults are (Leung, 2003). Although this age group might be interested in feedback on lifestyle behaviors (De Nooijer, Veling, Ton, De Vries, \& De Vries, 2008), they are, in contrast to older people who are more often confronted with chronic diseases, not likely to be internally motivated to invest time in health behavior change interventions (De Nooijer et al., 2005). This age group is, however, an important target group for health promotion, because many health risk behaviors are acquired during this period in life and may track to a certain extent into adulthood, thereby affecting not only current health but also health in later life (Kelder, Perry, Klepp, \& Lytle, 1994; Te Velde, Twisk, \& Brug, 2007). Hence, the focus of this study will be on Internet-delivered interventions aimed at adolescents or young adults.

A meta-analysis (Portnoy, Scott-Sheldon, Johnson, \& Carey, 2008) and systematic reviews (Myung, McDonnell, Kazinets, Seo, \& Moskowitz, 2009; Neville, O’Hara, \& Milat, 2009; Vandelanotte, Spathonis, Eakin, \& Owen, 2007) indicate that Internet-delivered interventions can be effective in changing behavior, even in comparison with face-to-face interventions (Steele, Mummery, \& Dwyer, 2009). Evidence from efficacy trials, however, indicates that exposure to these interventions is low, especially when they are implemented in real life (Bennett \& Glasgow, 2009; K. E. Evers, Cummins, Prochaska, \& Prochaska, 2005).

\footnotetext{
'Maastricht University/CAPHRI, Maastricht, the Netherlands ${ }^{2}$ Department of Public Health, Erasmus University Medical Centre, Rotterdam, the Netherlands

${ }^{3}$ EMGO Institute, VU University Medical Centre, Amsterdam, the Netherlands

Corresponding Author:

Rik Crutzen, Department of Health Promotion, Maastricht University, P.O. Box 616, Maastricht, 6200 MD Maastricht, The Netherlands Email: rik.crutzen@gvo.unimaas.nl
} 
Participants tend to spend only a limited amount of time at an intervention (Eysenbach, 2005). True exposure, that is, accessing the intervention website and actually using it, is necessary for an intervention to induce behavior changes. For Internetdelivered interventions, exposure consists of accessing the intervention website (i.e., a first visit), staying on the intervention website to actually use it, and revisiting the intervention website. The latter only applies to interventions that are developed to be visited multiple times. A systematic review of the literature was conducted to gain insight into the use and the effectiveness of methods and strategies aimed at facilitating exposure to Internet-delivered interventions. A more extensive exploration is timely, because this knowledge is crucial to improve the use of such interventions and, consequently, to increase behavioral change. Therefore, the following research questions (RQs) were formulated:

$R Q$ 1: Which methods and strategies are used to facilitate exposure to existing Internet-delivered interventions?

$R Q$ 2: On which theories or empirical data are these methods and strategies based?

$R Q 3$ : Which measures are used to assess exposure and how are these exposure measures linked to strategies to facilitate exposure?

$R Q$ 4: What are the potential effects of strategies to facilitate exposure and how are these related to their theoretical or empirical foundation?

Whereas a method is a theory-based technique, a strategy is a way of organizing, operationalizing, and delivering the method (Bartholomew, Parcel, Kok, \& Gottlieb, 2006). For example, sending e-mail messages to encourage participants to visit the intervention and set goals for reducing and eliminating cigarette use (An et al., 2006) would be a practical strategy based on the theory-based technique of goal setting. The concepts of methods and strategies are defined as such within the Intervention Mapping approach. This approach is used to design theory- and evidence-based health promotion programs and stresses the importance of having a theoretical and empirical foundation for decisions regarding the choice of methods and strategies (Bartholomew et al., 2006).

\section{Method}

A systematic review was conducted, according to the Cochrane guidelines (Higgins \& Green, 2006), to answer the research questions.

\section{Search Strategy}

We searched (February 18, 2008) the PubMed, PsycINFO, and Web of Science databases using the following query: (Internet* OR web* OR online*) AND (prevention OR intervention OR "health promotion" OR "health education" OR "health communication" OR (behav* AND change)). The search was limited to the time period January 1, 1995-January 1, 2008, and to literature in English. We deliberately used a very broad search strategy to include firstly as much literature as possible and to reduce the possibility of omissions.

\section{Selection Criteria}

A study was eligible for inclusion when describing the evaluation (in an original article published in a peer-reviewed journal) of an Internet-delivered intervention aimed at the primary prevention of physical chronic diseases through behavior change, targeted at adolescents or young adults (aged 12-25). The intervention should consist of a website offered in a noncontrolled setting or a controlled setting (e.g., class period) with freedom to navigate. The latter restriction was added because an intervention consisting of a website without freedom to navigate (i.e., linear) offered in a controlled setting would lead participants to use the intervention website as desired, but would make it impossible to study the effectiveness of methods and strategies used to facilitate exposure. The intervention should be targeted at end users (not intermediaries), aged 12-25, from the general public (not patients or institutionalized participants). The study being reported in accordance with the CONSORT Statement (Moher, Schulz, \& Altman, 2001) was not a selection criterion, because our focus was on exposure to the intervention instead of the intervention's effectiveness regarding behavior change.

\section{Review Procedure}

The review procedure comprised three phases to identify relevant studies and was performed independently by two reviewers using the selection criteria described above. During the first phase, studies were reviewed based on title only. We used the most conservative approach, meaning that if in doubt, studies were included for the second phase during which they were reviewed based on their abstract. If still in doubt, we included the study for the third phase during which the full article was reviewed. After this phase, both reviewers (RC and $\mathrm{JdN}$ ) discussed whether studies met the inclusion criteria until agreement was reached. To identify more eligible studies, the same procedure was repeated for articles in reference lists of included studies.

\section{Data Abstraction}

A standardized extraction form was used to summarize intervention and sample characteristics, methods and strategies that could facilitate exposure, theories or empirical data on which they were based, and exposure measures. Two reviewers ( $\mathrm{RC}$ and $\mathrm{JdN}$ ) independently gathered the relevant 
information and discussed this afterwards to improve the reliability of their data abstraction. Methods and strategies were labeled for the sake of clarity, and both reviewers fully agreed on this labeling. This systematic review was explorative in nature and we decided on labeling after data abstraction and based this labeling on the methods and strategies used in interventions that were included in the final sample. The reason for this decision was that we did not want to exclude any methods or strategies a priori and to guarantee openness regarding methods and strategies that are used in practice. The categorization of health communication by Hawkins, Kreuter, Resnicow, Fishbein, and Dijkstra (2008) was used to separate targeted communication from tailored communication. Corresponding authors of included studies were contacted by e-mail (April, 2008) to complete the extraction forms (if the information provided in the article was insufficient). Initially, the authors had 3 weeks to respond, but we sent a reminder by e-mail after 3 weeks to increase the response rate (May, 2008).

\section{Results}

More than 12,000 titles were initially identified because of the broad search strategy. A total of 838 studies were selected on the basis of their title, of which 26 studies met the eligibility criteria. There was full agreement between the two reviewers, although it is possible that there were multiple and different reasons why a study could be excluded. Of the 119 studies that were included based on their abstract but excluded based on the full article, the primary reasons for rejection were as follows: no evaluation study $(10.1 \%, n=12)$; the study was not published as an original article in a peer-reviewed journal $(2.5 \%, n=3)$; the study did not describe an intervention aimed at primary prevention of physical chronic diseases through behavior change $(11.8 \%, n=14)$; the intervention was not targeted at adolescents or young adults (aged 12-25) $(58.0 \%$, $n=69)$; the intervention did not (at least partly) consist of a website $(10.1 \%, n=12)$; the intervention was not offered in a noncontrolled setting or a controlled setting with freedom to navigate $(7.6 \%, n=9)$. Figure 1 gives an overview of the different phases of the review procedure. These 26 studies described 22 interventions that were related to smoking cessation (8), sexual behavior (4), alcohol use (4), physical activity (2), nutrition (1), physical activity and nutrition (1), health and lifestyles in general (1), and weight loss (1) (Table 1).

All corresponding authors $(n=21)$ were contacted, of whom $14(67 \%)$ responded to our request to complete the extraction forms. Tables 1 and 2 summarize all data abstracted from the articles and information provided by the corresponding authors and were used to answer our research questions. Five interventions were excluded from these tables (Chen, Yeh, \& Chao, 2006; Chiauzzi, Green, Lord, Thum, \& Goldstein, 2005; W. Evers \& Carol, 2007; Obermayer, Riley, Asif, \& Jean-Mary, 2004; Walters, Vader, \& Harris, 2007), because exposure measures were unavailable, resulting in data from 17 interventions for the present review.

\section{RQ I: Which Methods and Strategies Are Used to Facilitate Exposure to Existing Internet-Delivered Interventions? (Table I)}

Nine interventions customized their information to a certain extent. According to the categorization of health communication by Hawkins et al. (2008), five interventions used targeted communication (defined as group targeted, e.g., appealing for African American teenage girls) and six interventions used tailored communication (defined as individually tailored, e.g., personal feedback). Three of those six interventions combined tailored communication with monitoring of health behavior (change).

Nine interventions offered facilities to support their participants, either through professionals (e.g., ask-the-expert; six interventions) or peers (six interventions). Peer support was enabled through sharing of information (e.g., personal experiences with behavior change) or direct communication with other peers. Four interventions offered a discussion board or forum to facilitate opportunities to support.

Several strategies have been used with regard to the delivery of the intervention's content. Five interventions provided content in an interactive way. Content was made easily accessible (e.g., through a simple linear design instead of a more open design with freedom to choose) by four interventions. Conditional progress, meaning that participants can only access certain modules or parts of a website once the previous are finished or during a certain time period, was used by two interventions.

Other strategies were to embed the Internet-delivered intervention in a social context (e.g., link it to school assignments; three interventions), the use of reminders to visit or revisit or invitations to participate (either physical or through e-mail; seven interventions), and the use of incentives (six interventions).

\section{RQ2: On Which Theories or Empirical Data Are These Methods and Strategies Based? (Table 2)}

As shown in the second column of Table 2, social learning (cognitive) theory (Patten et al., 2006; Patten et al., 2007; Suminski \& Petosa, 2006), the transtheoretical model (Escoffery, McCormick, \& Bateman, 2004), the informationmotivation-behavioral skills model (Barak \& Fisher, 2003), self-regulation theory, and the theoretical fields of social support (Escoffery et al., 2004; Marks et al., 2006) and social norms (Saitz et al., 2007; Thombs et al., 2007) were described as the basis for methods and strategies. Although the aim of these theories is to explain behavior or the process of behavior change, the methods and strategies that are derived from 


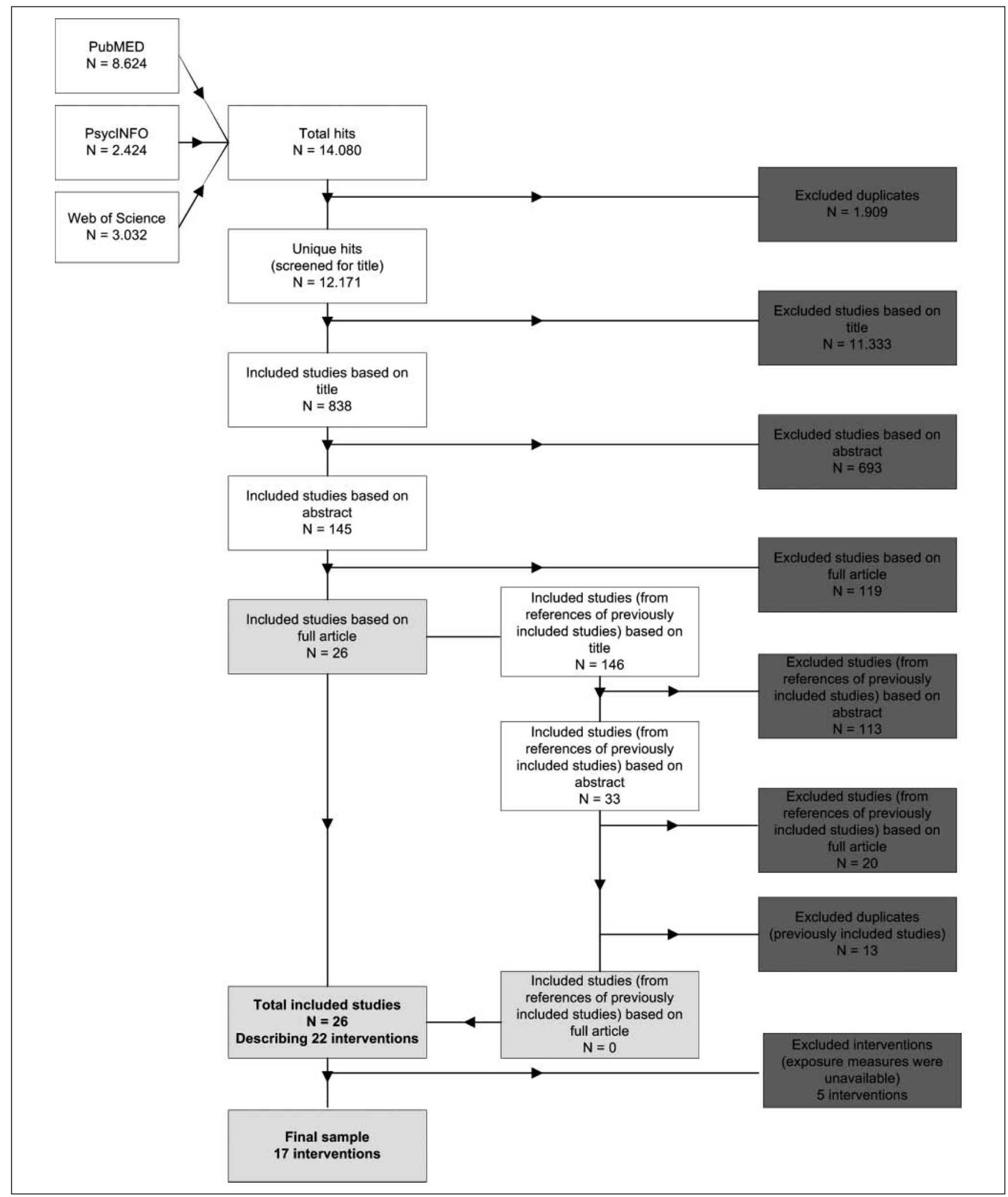

Figure I. Flow-chart review procedure 


$$
B
$$




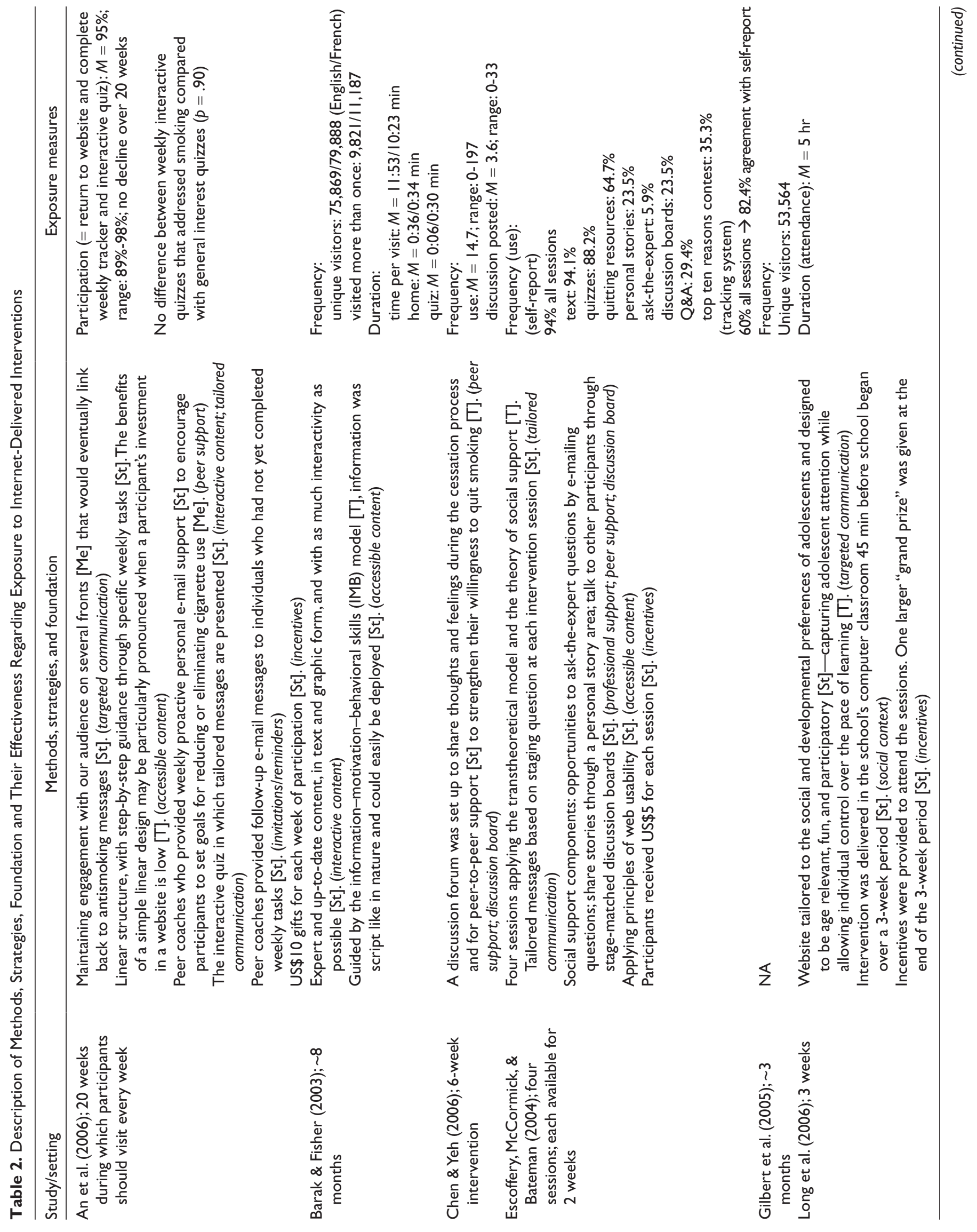




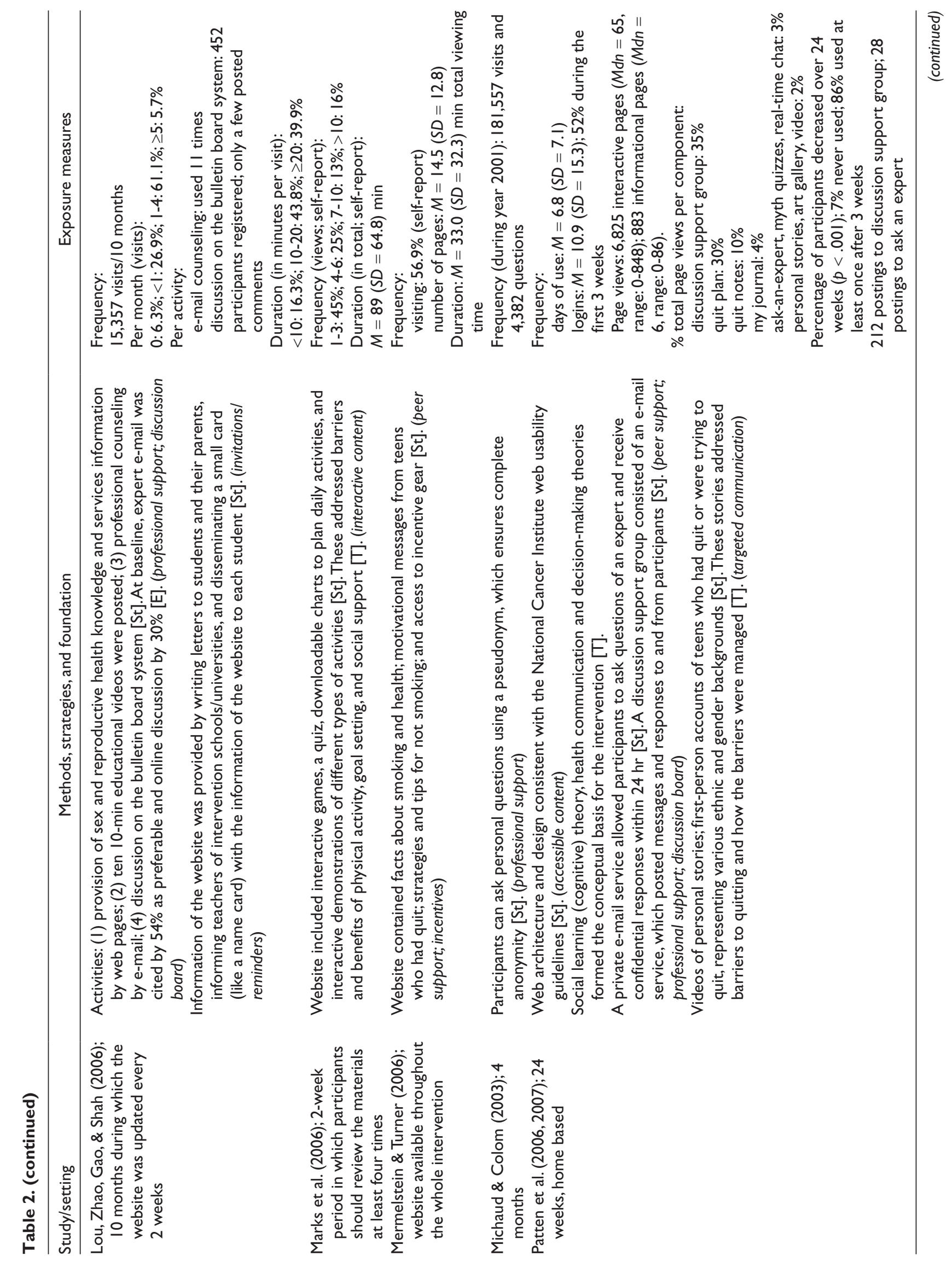




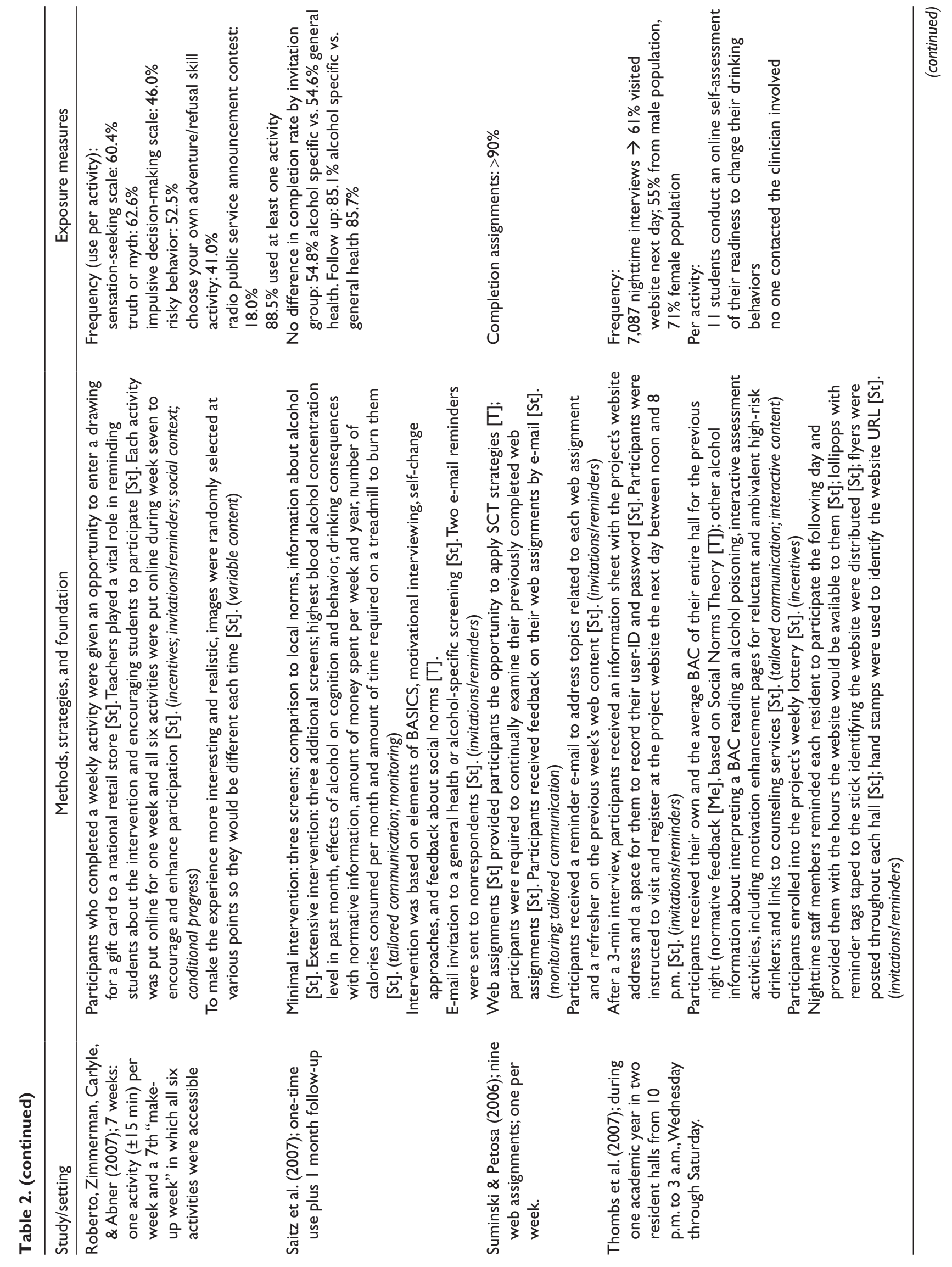




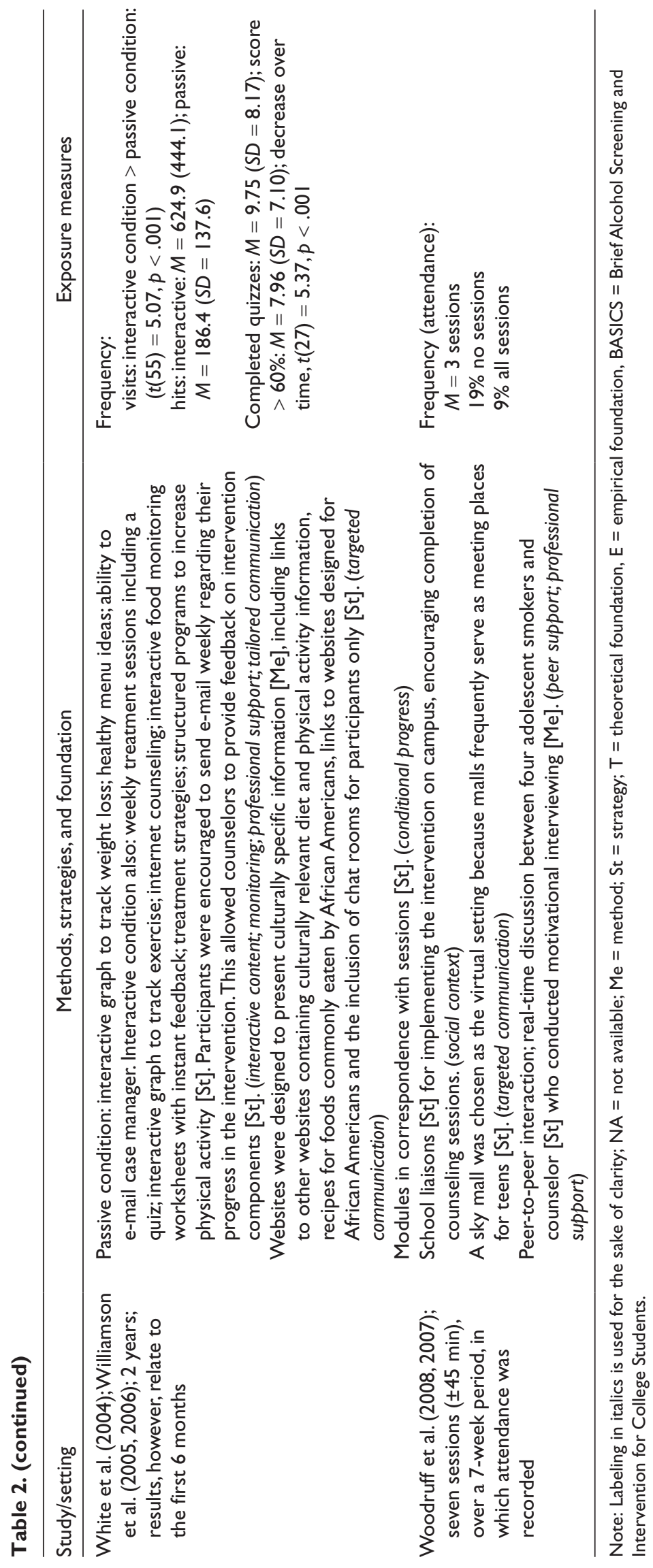


these theories could also be used to facilitate exposure. For example, offering a game (a peripheral cue in terms of the elaboration likelihood model that aims to explain attitude change) in which participants had to crush virtual cigarettes led to an increase in exposure to a 12 -week psychosocial minimal-support treatment program (Girard, Turcotte, Bouchard, $\&$ Girard, 2009). Furthermore, some theoretical assumptions were described without explicitly mentioning an underlying theory. For example, one study (An et al., 2006) described that the benefits of a simple linear design may be particularly pronounced when a participant's investment in a website is low without referring to a theory or empirical data. Empirical data as a basis for methods and strategies (e.g., needs assessment) was barely described. If so, participants' preferences (e.g., communication through e-mail or discussion board) were investigated during the development process (Lou, Zhao, Gao, \& Shah, 2006).

\section{RQ3: Which Measures Are Used to Assess Exposure and How Are These Exposure Measures Linked to Strategies to Facilitate Exposure? (Table I and 2)}

The number of (unique) visitors was mostly reported, but several other measures were also used to assess exposure, for example, frequency of visiting, duration of visit, and number of pages visited, as shown in the third column of Table 2. Furthermore, whether certain tasks were conducted was also used as an exposure measure. For each intervention, however, only a few of these measures were reported, resulting in a heterogeneous description of exposure to intervention websites.

Twelve interventions used objectively tracked exposure measures (e.g., by means of server data), one intervention relied on self-reported exposure measures, and two interventions combined both methods. (Escoffery et al., 2004, reported $82.4 \%$ agreement between objectively tracked and selfreported exposure measures.) The remaining two interventions were session based, and only participants' attendance to these sessions was recorded.

Nine of those 17 interventions reported exposure measures per component, which made it possible to link them to strategies used. Furthermore, two of those nine interventions made a distinction between interactive and non-interactive content. Eight interventions reported exposure measures for the intervention's website as a whole.

\section{RQ4:What Are the Potential Effects of Strategies to Facilitate Exposure and How Are These Related to Their Theoretical or Empirical Foundation? (Tables I and 2)}

Results of those nine interventions that reported exposure measures per component showed that discussion boards were only moderately used for peer support. For example, 452 participants registered on a discussion board regarding sexual and reproductive health, but only a few comments were posted (Lou et al., 2006). Although professional support (e.g., ask-the-expert) was often provided, it was only limitedly used. From those interventions that made a distinction between interactive and noninteractive content, it appeared that providing content in a more interactive way resulted in higher exposure. In an Internet-based lifestyle behavior modification intervention for weight management, participants in the interactive condition visited the website more often than participants in the passive condition, $t(55)=5.07, p<.001$ (White et al., 2004; Williamson et al., 2005; Williamson et al., 2006). Descriptive statistics of a website for adolescent smoking cessation indicated more page views for interactive pages compared to informational pages $(M d n=65$ vs. $M d n=6$; Patten et al., 2006; Patten et al., 2007).

Other interventions used a combination of several methods and strategies, which complicates dismantling the effectiveness to single methods and strategies by looking at exposure measures with regard to the intervention's website as a whole. The combination of tailored communication, the use of reminders to visit or revisit or invitations to participate, and the use of incentives, however, resulted in high exposure to Internet-delivered interventions. In an online college-life magazine targeting college smokers, for example, on average $95 \%$ of participants returned weekly to the website and completed a tracker and interactive quiz. Notably, there was no decline over 20 weeks (An et al., 2006). In another intervention, designed to deter alcohol use in residence halls, $61 \%$ visited the website the day after they consumed alcohol (Thombs et al., 2007).

It is premature to draw definite conclusions regarding effectiveness of strategies to facilitate exposure, because their use was inconsistently linked to exposure measures. Moreover, it was difficult to relate effectiveness to theories or empirical data that served as the ground for the use of methods and strategies, because theories or empirical data were hardly linked to exposure measures.

\section{Discussion}

This systematic review resulted in an overview of methods and strategies that have been used to facilitate exposure to Internet-delivered interventions aimed at adolescents or young adults. It appeared that frequently used strategies (e.g., ask-the-expert, discussion boards) were moderately or even seldom used by adolescents or young adults, even though they were suggested by experts (Crutzen et al., 2008b) and the target group (Crutzen et al., 2008a) as factors that might be associated with exposure to Internet-delivered interventions in previous studies. Interventions that combined several strategies were most effective with regard to facilitating exposure. As most interventions used a combination of several strategies, it is rendered more difficult to study the 
effectiveness of single strategies. It is recommended to conduct experimental research in more controlled settings to increase evidence-based insight into their effectiveness regarding exposure, before applying these strategies in practice. Furthermore, a meta-analytical approach can be used to detect robust effects regarding the effectiveness of certain strategies (e.g., the use of reminders; Göritz \& Crutzen, 2010).

In the studies included in the review, there was only a limited description of the strategies or efforts taken to facilitate exposure to the intervention. This knowledge is crucial, however, to get more insight into ways to improve exposure to Internet-delivered interventions and consequently, to increase behavioral change. In addition to a description of the educational content of an Internet-delivered intervention, future studies should also describe which strategies they have used specifically to attract attention to the intervention and to make using the intervention and revisiting it (when applicable) attractive (Danaher \& Seeley, 2009), to gain more insight into potential effective strategies to improve exposure.

Although most studies did make explicit what theory was used to inform the intervention, these theories were primarily behavior determinants or behavior change theories. No exposure-specific theories were mentioned in the reviewed studies. Therefore, more attention should be paid to the development and application of theories regarding exposure, from which methods and strategies can be derived. This recommendation has also been acknowledged within the field of mental health (Christensen, Griffiths, \& Farrer, 2009).

Moreover, it remains unclear how we decide whether methods and strategies regarding Behavior A are also applicable to Behavior B. A recent review has focused on similarities between behavior-specific determinants of four health behaviors: smoking, (binge) drinking, safe sex, and healthy nutrition (Peters et al., 2009). Although several determinants were found to be relevant for all four behaviors, 51 of a total of 86 determinants could not be classified meaningfully to a higher level or have only been studied for one behavior. Other research has shown that addictive behaviors (smoking, alcohol consumption; De Vries et al., 2008) and energy balance-related behaviors (physical activity, fruit consumption; Kremers, De Bruijn, Schaalma, \& Brug, 2004) are clustered. This stresses the possible difficulty to generalize findings regarding strategies to facilitate exposure to Internet-delivered interventions from one health behavior to others. Hence, effective strategies can be derived from Internet-delivered interventions focusing on different behaviors, but behavior-specific evidence-based insight needs to be gained.

It is premature, because of the heterogeneity of exposure measures and inconsistent linkage of these exposure measures to strategies used in Internet-delivered interventions, to make a valid comparison between strategies used in these interventions and theories or empirical data on which they are based. More uniformity in reporting exposure measures would make it possible to compare or pool the results of various studies.
This is in line with recommendations for exposure measures regarding "offline" interventions, for example national campaigns (Southwell, Barmada, Hornik, \& Maklan, 2002) and community-based interventions (Morris, 2009).

\section{Implications for Practice}

This overview can be useful for practice to choose potential strategies to be used in Internet-delivered interventions to improve exposure. It needs to be stressed that methods and strategies that have been used to facilitate exposure do not need to be applied separately. For example, providing content in an interactive way can be combined with monitoring health behavior and behavior change. Furthermore, during the development of an Internet-delivered intervention, strategies can also be derived from interventions focusing on different behaviors. For example, if one develops an Internet-delivered intervention that aims to promote safe sex behaviors, one may look at Internet-delivered interventions related to smoking cessation to get ideas about certain strategies. However, this does not guarantee the effectiveness of these strategies in the context of promoting safe sex behaviors.

With regard to exposure measures, it is recommended to track and report multiple exposure measures (e.g., frequency of visiting, duration of visit, and number of pages visited; Crutzen, De Nooijer, Candel, \& De Vries, 2008). Each exposure measure relates to a different aspect of exposure (Danaher, Boles, Akers, Gordon, \& Severson, 2006). One can visit an intervention very frequently, for example, but only for a short period of time. Duration of visits, on the other hand, does not necessarily give a clear picture of participants' online activity, because one does not know what parts of the intervention website are actually used. Therefore, the number of visited webpages would be more appropriate to assess online activity (Crutzen, 2009). Most exposure measures can be tracked objectively, which is preferable above self-reported exposure measures that are dependent on participants' memory, interpretation, and social desirability bias. If exposure measures were linked to intervention outcome measures at the individual level, it would also be possible to study potentially effects of exposure on these outcome measures.

There are no known technical barriers to track exposure measures of Internet-delivered interventions. It is important, however, to realize this from the start of an intervention development process and to involve technical staff during this initial phase (Crutzen et al., 2009). We recommend tracking as many exposure measures as possible because there is no gold standard (Crutzen, 2009). Furthermore, having exposure measures available is also useful during process evaluation of Internet-delivered interventions, as has been shown in other studies (Barak \& Fisher, 2003; Lou et al., 2006; Patten et al., 2007; Roberto, Zimmerman, Carlyle, \& Abner, 2007). These exposure measures provide detailed insight into where participants either leave the intervention website or have come to a standstill. This information can be used to adapt 
interventions to users' needs and therewith increase exposure rates and probability of behavior change.

\section{Limitations}

The process of dissemination was described only to a limited extent in the included studies, and most interventions were applied in a research setting and participants were recruited to participate in a study. Although the focus of this review was not on dissemination of Internet-delivered interventions, successful dissemination is required before participants can be exposed to the intervention. Dissemination involves the distribution of the intervention among the target population, including bringing the intervention to the attention of the target population. Successful dissemination depends on the target population, the source, and the intervention itself (Rogers, 2003). It needs to be stressed that server registrations can be used during the process of dissemination to determine where your visitors came from (e.g., banner ads, links from other websites).

Incentives and advertisements that were used to increase attention mostly focused on convincing people to participate in a study instead of an intervention and target sample sizes were based on power calculations instead of the public health impact if the Internet-delivered intervention would be implemented in real-life. In general, use of incentives is a strategy that is probably inapplicable once an Internet-delivered intervention is implemented in real-life, because this would increase costs enormously. Nevertheless, other incentives, for example, the receipt of valued information of social reinforcers, might be more useful in practice. Furthermore, embedding an Internetdelivered intervention in a social context could be defined as a feasible and appropriate way to disseminate it, for example, by linking the intervention to school activities (Crutzen, De Nooijer, \& De Vries, 2008). The feasibility, appropriateness, and effectiveness of such a social context could be explained by the infrastructure being available and intermediaries (e.g., teachers) being accustomed to such settings (e.g., providing education during class hours) (Reinaerts, De Nooijer, \& De Vries, 2007).

Sixty-seven percent of corresponding authors responded to our request to complete the extraction forms. A possible explanation why other authors did not respond could be that they did not want to provide the information we requested because it was unavailable or would create negative publicity regarding their intervention. Although this nonresponse and a possible publication bias might have skewed the results, we think that this is not the case because the included studies were aimed at assessing the efficacy of Internet-delivered interventions and not to test strategies that facilitate exposure. Furthermore, corresponding authors were very willing to share information regarding their intervention. This resulted, however, in very little new information. Therefore, it remains unclear whether information with regard to exposure methods, strategies, and their effectiveness was unavailable or not meant to be shared.

Finally, included studies were limited to original articles published in peer-reviewed English-language journals, and strict inclusion and exclusion criteria were followed. In our zeal to be parsimonious and systematic in our review, we may have discarded other potentially valuable studies (e.g., Buller et al., 2008).

\section{Conclusion}

The results of this systematic review revealed potential strategies that can be used in practice to facilitate exposure to Internet-delivered interventions (e.g., the combination of tailored communication and the use of reminders and incentives) and stress the importance of tracking and reporting exposure measures. Moreover, the formation of further research questions regarding effectiveness of specific strategies is deemed necessary to fully utilize the potential of Internet-delivered interventions and increase their public health impact.

\section{Acknowledgements}

The authors would like to thank Babs Franssen for her assistance during the first two phases of the review procedure.

\section{Declaration of Conflicting Interests}

The authors declared no conflicts of interests with respect to the authorship and/or publication of this article.

\section{Funding}

The authors disclosed receipt of the following financial support for the research and/or authorship of this article:

This work was supported by a grant from ZonMw - the Netherlands Organization for Health Research and Development [grant 4016.0017].

\section{References}

An, L. C., Perry, C. L., Lein, E. B., Klatt, C., Farley, D. M., Bliss, R. L., ... Ehlinger, E. P. (2006). Strategies for increasing adherence to an online smoking cessation intervention for college students. Nicotine \& Tobacco Research, 8(Suppl. 1), S7-S12.

Barak, A., \& Fisher, W. A. (2003). Experience with an Internet-based, theoretically grounded educational resource for the promotion of sexual and reproductive health. Sexual and Relationship Therapy, 18, 293-308.

Bartholomew, L. K., Parcel, G. S., Kok, G., \& Gottlieb, N. H. (2006). Planning health promotion programs: An intervention mapping approach. San Francisco, CA: Jossey-Bass.

Bennett, G. G., \& Glasgow, R. E. (2009). The delivery of public health interventions via the Internet: Actualizing their potential. Annual Review of Public Health, 30, 273-292.

Bernhardt, J. M., \& Hubley, J. (2001). Health education and the Internet: The beginning of a revolution. Health Education Research, 16, 643-645.

Buller, D. B., Borland, R., Woodall, W. G., Hall, J. R., Hines, J. M., Burris-Woodall, P., ... Saba, L. (2008). Randomized trials of Consider This, a tailored, Internet-delivered smoking prevention program for adolescents. Health Education \& Behavior, 35, 260-281.

Chen, H.-H., \& Yeh, M.-L. (2006). Developing and evaluating a smoking cessation program combined with an Internet-assisted 
instruction program for adolescents with smoking. Patient Education and Counseling, 61, 411-418.

Chen, H.-H., Yeh, M.-L., \& Chao, Y.-H. (2006). Comparing effects of auricular acupressure with and without an Internet-assisted program on smoking cessation and self-efficacy of adolescents. Journal of Alternative and Complementary Medicine, 12, 147-152.

Chiauzzi, E., Green, T. C., Lord, S., Thum, C., \& Goldstein, M. (2005). My student body: A high-risk drinking prevention web site for college students. Journal of American College Health, 53, 263-274.

Christensen, H., Griffiths, K. M., \& Farrer, L. (2009). Adherence in Internet interventions for anxiety and depression: Systematic review. Journal of Medical Internet Research, 11, e13.

Crutzen, R. (2009). Utilising exposure measures of Internet-delivered interventions. In E. Olsen (Ed.), Behaviour change \& technology. Oslo: Changetech.

Crutzen, R., De Nooijer, J., Brouwer, W., Oenema, A., Brug, J., \& De Vries, N. K. (2008a). Internet-delivered interventions aimed at adolescents: A Delphi study on dissemination and exposure. Health Education Research, 23, 427-439.

Crutzen, R., De Nooijer, J., Brouwer, W., Oenema, A., Brug, J., \& De Vries, N. K. (2008b). Qualitative assessment of adolescents' views about improving exposure to Internet-delivered interventions. Health Education, 108, 105-116.

Crutzen, R., De Nooijer, J., Brouwer, W., Oenema, A., Brug, J., \& De Vries, N. K. (2009). A conceptual framework for understanding and improving adolescents' exposure to Internet-delivered interventions. Health Promotion International, 24, 277-284.

Crutzen, R., De Nooijer, J., Candel, M. J. J. M., \& De Vries, N. K. (2008). Adolescents who intend to change multiple health behaviours choose greater exposure to an Internet-delivered intervention. Journal of Health Psychology, 13, 906-911.

Crutzen, R., De Nooijer, J., \& De Vries, N. K. (2008). How to reach a target group with Internet-delivered interventions? European Health Psychologist, 10, 77-79.

Danaher, B. G., Boles, S. M., Akers, L., Gordon, J. S., \& Severson, H. H. (2006). Defining participant exposure measures in web-based health behavior change programs. Journal of Medical Internet Research, 8, e15.

Danaher, B. G., \& Seeley, J. R. (2009). Methodological issues in research on web-based behavioral interventions. Annals of Behavioral Medicine, 38, 28-39.

De Nooijer, J., Oenema, A., Kloek, G., Brug, J., De Vries, H., \& De Vries, N. K. (2005). Bevordering van Gezond Gedrag via Internet: $\mathrm{Nu}$ en in de Toekomst [Promotion of healthy behavior through the internet: Now and in the future]. Maastricht, Netherlands: Maastricht University.

De Nooijer, J., Veling, M. L., Ton, A., De Vries, H., \& De Vries, N. K. (2008). Electronic monitoring and health promotion: The evaluation of the E-MOVO website by adolescents. Health Education Research, 23, 382-391.

De Vries, H., Van 't Riet, J., Spigt, M., Metsemakers, J., Van den Akker, M., Vermunt, J. K., \& Kremers, S. (2008). Clusters of lifestyle behaviors: Results from the Dutch SMILE study. Preventive Medicine, 46, 203-208.
Escoffery, C., McCormick, L., \& Bateman, K. (2004). Development and process evaluation of a web-based smoking cessation program for college smokers: Innovative tool for education. Patient Education and Counseling, 53, 217-225.

Evers, K. E., Cummins, C. O., Prochaska, J. O., \& Prochaska, J. M. (2005). Online health behavior and disease management programs: Are we ready for them? Are they ready for us? Journal of Medical Internet Research, 7, e27.

Evers, W., \& Carol, B. (2007). An Internet-based assessment tool for food choices and physical activity behaviors. Journal of Nutrition Education and Behavior, 39, 105-106.

Eysenbach, G. (2005). The law of attrition. Journal of Medical Internet Research, 7, e11.

Gilbert, L. K., Temby, J. R. E., \& Rogers, S. E. (2005). Evaluating a teen STD prevention web site. Journal of Adolescent Health, 37, 236-242.

Girard, B., Turcotte, V., Bouchard, S., \& Girard, B. (2009). Crushing virtual cigarettes reduces tobacco addiction and treatment discontinuation. CyberPsychology \& Behavior, 12, 477-483.

Göritz, A. S., \& Crutzen, R. (2010). Reminders in web-based data collection: Increasing response rates at the price of retention. Manuscript submitted for publication.

Hawkins, R. P., Kreuter, M. W., Resnicow, K., Fishbein, M., \& Dijkstra, A. (2008). Understanding tailoring in communicating about health. Health Education Research, 23, 454-466.

Higgins, J. P. T., \& Green, S. (2006). Cochrane handbook for systematic reviews of interventions 4.2.6 [updated September 2006]. Chichester, UK: Wiley.

Kelder, S. H., Perry, C. L., Klepp, K. I., \& Lytle, L. L. (1994). Longitudinal tracking of adolescent smoking, physical activity, and food choice behaviors. American Journal of Public Health, 84, 1121-1126.

Kremers, S. P. J., De Bruijn, G. J., Schaalma, H., \& Brug, J. (2004). Clustering of energy balance-related behaviours and their intrapersonal determinants. Psychology \& Health, 19, 595-606.

Leung, L. (2003). Impacts of Net-generation attributes, seductive properties of the Internet, and gratifications-obtained on Internet use. Telematics and Informatics, 20, 107-129.

Long, J. D., Armstrong, M. L., Amos, E., Shriver, B., Roman-Shriver, C., Feng, D., . . . Blevins, M. W. (2006). Pilot using World Wide Web to prevent diabetes in adolescents. Clinical Nursing Research, $15,67-79$.

Lou, C. H., Zhao, Q., Gao, E. S., \& Shah, I. H. (2006). Can the Internet be used effectively to provide sex education to young people in China? Journal of Adolescent Health, 39, 720-728.

Marks, J. T., Campbell, M. K., Ward, D. S., Ribisl, K. M., Wildemuth, B. M., \& Symons, M. J. (2006). A comparison of web and print media for physical activity promotion among adolescent girls. Journal of Adolescent Health, 39, 96-104.

Mermelstein, R., \& Turner, L. (2006). Web-based support as an adjunct to group-based smoking cessation for adolescents. Nicotine \& Tobacco Research, 8, S69-S76.

Michaud, P.-A., \& Colom, P. (2003). Implementation and evaluation of an Internet health site for adolescents in Switzerland. Journal of Adolescent Health, 33, 287-290. 
Moher, D., Schulz, K. F., \& Altman, D. G. (2001). The CONSORT Statement: Revised recommendations for improving the quality of reports of parallel-group randomized trials. Annals of Internal Medicine, 134, 657-662.

Morris, D. S. (2009). Measuring exposure to health messages in community-based intervention studies: A systematic review of current practices. Health Education \& Behavior, 36, 979-998.

Myung, S.-K., McDonnell, D. D., Kazinets, G., Seo, H. G., \& Moskowitz, J. M. (2009). Effects of web- and computer-based smoking cessation programs. Archives of Internal Medicine, 169, 929-937.

Neville, L. M., O’Hara, B., \& Milat, A. J. (2009). Computer-tailored dietary behaviour change interventions: A systematic review. Health Education Research, 24, 699-720.

Obermayer, J. L., Riley, W. T., Asif, O., \& Jean-Mary, J. (2004). College smoking-cessation using cell phone text messaging. Journal of American College Health, 53, 71-78.

Patten, C. A., Croghan, I. T., Meis, T. M., Decker, P. A., Pingree, S., Colligan, R. C., . . Gustafson, D. H. (2006). Randomized clinical trial of an Internet-based versus brief office intervention for adolescent smoking cessation. Patient Education and Counseling, 64, 249-258.

Patten, C. A., Rock, E., Meis, T. M., Decker, P. A., Colligan, R. C., Pingree, S., . . Gustafson, D. H. (2007). Frequency and type of use of a home-based, Internet intervention for adolescent smoking cessation. Journal of Adolescent Health, 41, 437-443.

Peters, L. W. H., Wiefferink, C. H., Hoekstra, F., Buijs, G. J., Ten Dam, G. T. M., \& Paulussen, T. G. W. M. (2009). A review of similarities between domain-specific determinants of four health behaviors among adolescents. Health Education Research, 24, 198-223.

Portnoy, D. B., Scott-Sheldon, L. A. J., Johnson, B. T., \& Carey, M. P. (2008). Computer-delivered interventions for health promotion and behavioral risk reduction: A meta-analysis of 75 randomized controlled trials, 1988-2007. Preventive Medicine, 47, 3-16.

Reinaerts, E., De Nooijer, J., \& De Vries, N. K. (2007). Fruit \& vegetable distribution program versus a multi component program to increase F\&V consumption: Which should be recommended for implementation? Journal of School Health, 77, 679-686.

Roberto, A. J., Zimmerman, R. S., Carlyle, K. E., \& Abner, E. L. (2007). A computer-based approach to preventing pregnancy, STD, and HIV in rural adolescents. Journal of Health Communication, 12, 53-76.

Roberts, D. F., \& Foehr, U. G. (2008). Trends in media use. The Future of Children, 18, 11-37.

Rogers, E. M. (2003). Diffusion of innovations. New York, NY: Free press.
Saitz, R., Palfai, T. P., Freedner, N., Winter, M. R., MacDonald, A., Lu, J., . . . Dejong, W. (2007). Screening and brief intervention online for college students: The iHealth study. Alcohol and Alcoholism, 42, 28-36.

Southwell, B. G., Barmada, C. H., Hornik, R. C., \& Maklan, D. M. (2002). Can we measure encoded exposure? Validation evidence from a national campaign. Journal of Health Communication, 7, 445-453.

Steele, R. M., Mummery, W. K., \& Dwyer, T. (2009). A comparison of face-to-face or Internet-delivered physical activity intervention on targeted determinants. Health Education \& Behavior, 36, 1051-1064.

Suminski, R. R., \& Petosa, R. (2006). Web-assisted instruction for changing social cognitive variables related to physical activity. Journal of American College Health, 54, 219-225.

Te Velde, S. J., Twisk, J. W. R., \& Brug, J. (2007). Tracking of fruit and vegetable consumption from adolescence into adulthood and its longitudinal association with overweight. British Journal of Nutrition, 98, 431-438.

Thombs, D. L., Olds, R. S., Osborn, C. J., Casseday, S., Glavin, K., \& Berkowitz, A. D. (2007). Outcomes of a technology-based social norms intervention to deter alcohol use in freshman residence halls. Journal of American College Health, 55, 325-332.

Vandelanotte, C., Spathonis, K. M., Eakin, E. G., \& Owen, N. (2007). Website-delivered physical activity interventions: A review of the literature. American Journal of Preventive Medicine, 33, 54-64.

Walters, S. T., Vader, A. M., \& Harris, T. R. (2007). A controlled trial of Web-based feedback for heavy drinking college students. Prevention Science, 8, 83-88.

White, M. A., Martin, P. D., Newton, R. L., Walden, H. M., YorkCrowe, E. E., Gordon, S. T., . . . Williamson, D. A. (2004). Mediators of weight loss in a family-based intervention presented over the Internet. Obesity Research, 12, 1050-1059.

Williamson, D. A., Martin, P. D., White, M. A., Newton, R., Walden, H., York-Crowe, E., . . . Ryan, D. (2005). Efficacy of an Internetbased behavioral weight loss program for overweight adolescent African-American girls. Eating and Weight Disorders, 10, 193-203.

Williamson, D. A., Walden, H. M., White, M. A., York-Crowe, E., Newton, R. L., Alfonso, A., . . Ryan, D. (2006). Two-year Internet-based randomized controlled trial for weight loss in African-American girls. Obesity, 14, 1231-1243.

Woodruff, S. I.,Conway, T. L., \& Edwards, C. C. (2008). Sociodemographic and smoking-related psychosocial predictors of smoking behavior change among high school smokers. Addictive Behaviors, 33, 354-358.

Woodruff, S. I., Conway, T. L., Edwards, C. C., Elliott, S. P., \& Crittenden, J. (2007). Evaluation of an Internet virtual world chat room for adolescent smoking cessation. Addictive Behaviors, 32(9), 1769-1786. 